\title{
A Feasibility Study of Error Analysis on the Teaching of Chinese-English Translation-A Case Study of Non-English Major Freshmen in BUPT
}

\author{
Yunhong Zhang \\ School of Humanities, Beijing University of Posts and Telecommunications, Beijing, China \\ Email: zhangyunhong3656@sina.com \\ Baoling Wang \\ School of Humanities, Beijing University of Posts and Telecommunications, Beijing, China \\ Email: baolingwang2006@gmail.com
}

\begin{abstract}
Error Analysis is one of the most common methods in statistics. According to Corder S. P (1967) error is significant to learners. This paper applies it to the teaching of Chinese-English translation. Taking a whole class as a research unit and by analyzing the common errors made by students in their homework, the researcher records the error types, numbers of each type of error as well as the corresponding frequencies separately. Then the researcher lists out the top six errors and calculates the total frequency of them (total percentage of the six errors occupied in the class). After the analysis, the teacher feedbacks the results to the students as well as explains the methods of error identification and correction. This paper compares two non-English major classes with 60 freshmen; one has adopted "Error Analysis" in the teaching of Chinese-English Translation, while the other has not. Finally after one semester, the class which has applied "Error Analysis" makes greater progress than the class not. From some aspects, the research does show that "Error Analysis Teaching Method" could promote the Chinese-English translating skills of non-English major freshmen. Though this research has its limitations, it is valuable in improving the traditional translation teaching strategies.
\end{abstract}

Index Terms - error analysis on translation teaching, error analysis, Chinese-English translation, teaching experiment

\section{INTRODUCTION}

With the development of globalization, English is becoming more and more important. English has penetrated into every aspect of our life. Our products have English introduction and instructions in the packages, our road signs are written in two languages and our mobile service platforms provide English help. It is necessary to learn English well in order to adapt to the society.

Most Chinese students begin to learn English in their primary school, but due to the significant differences of the two languages, they can not do well in English even after they have become freshmen, especially in translating Chinese into English.

The present paper is devoted to analyzing the common errors made by freshmen in translating Chinese into English and tries to apply error analysis method to classroom in order to find out whether it is feasible or not.

The current paper is divided into five parts: (1) Introduction; (2) Literature Review; (3) Research Design; (4) Data Analysis; (5) Conclusion, Limitation and Implications.

\section{LITERATURE REVIEW}

\section{A. The Previous Studies on Translation Error Analysis for Students}

Many scholars have published their books and papers on student translation error analysis. Some even have proposed their own error correction strategies in their text.

In the current book market, there are plentiful of books named the common errors made by Chinese in Translating Chinese into English or something alike, such as the book by Chen Dezhang and Wang Fengxin. There are also some handbooks in this field, like Yang Guanghui's A Handbook for Analyzing the Errors Made by Middle School Students.

The research papers in this field are plentiful, too, such as "Some Enlightenments for Translation Course for Non-English Major Postgraduates from the Analysis of Their Errors in Translation", "Error Analysis and Strategies Research on Translation of Higher Vocational-Technical Schools" by Li Zhuqing and Wang Lei, "Analyzing the 
Common Errors Made by Non-English Major Freshmen" by Xing Chunxiao and Huang Xiuli, "Try to Analyze the Reasons that Cause these Errors in College English Translating Study" by Zhong Huilian), and "Analysis on Mistakes Often Made in College Chinese-English Translation" by Wei Dan, etc.

In conclusion, many achievements on translation error analysis for students have been made by scholars, and they have found some fundamental reasons of such errors and applied such analysis into classroom as well as put forward certain effective strategies that can help improve the traditional translation teaching.

Based on the former researches, the current paper will continue the research in its own way. This research adopts a quantitative research method. It not just analyzes the error types, but also analyzes the numbers and frequencies of each type of error clearly. It is a systematic research. The following chapters explain the research in detail.

\section{B. Theoretical Basis of this Research}

This paper is based on the theory of Translation Error Analysis and Statistic Contrastive Analysis.

Li Zhuqing and Wang Lei (2009) defined the two approaches as following:

Error Analysis is to analyze the common errors easily made by students and by a thorough and systematic analyzing, Error Analysis try to discover the regularities of foreign language learning process which is affected by Universal Grammars. One of the approaches is to analyze the error types, numbers and the corresponding frequencies based on the data collected.

As for Translation Error Analysis, it is to analyze the common errors made by students in language translation. By a thorough and systematic analysis, it will discover the regularities of language translation and put forward better translation strategies.

In this research, the writer takes the above-mentioned approach and analyzes the error types, numbers and the corresponding frequencies.

In statistics, contrastive analysis is to compare two or more different data groups in every aspect. It may compare two or more different objects, or just compare two or more different stages of the same object. Through comparison, it tries to find out the relationship between them

\section{RESEARCH DESIGN}

Together with the statistical process of Christopher D. Manning \& Hinrich Schütze (1999) as well as the contrastive analysis and error analysis approaches of Gao Yuan (2002) in Beijing University of Aeronautics and Astronautics, this research will adopt the research approach introduced by Gary D. Bouma and G.B.J. Atkinson in A Handbook of Social Science Research.

\section{A. Research Objective}

The present research is to analyze the common errors made by freshmen in their homework in translating Chinese into English and then apply the error analysis approach to the classroom in order to find whether it is feasible or not. The variables selected are error types, error number and error frequency. The fourteen types of errors on articles, possessives or pronouns, subject-verb agreement, the singular or plural form of nouns, uninterrupted sentences, passive voice, conjunction, infinitive, -ing form, Chinglish, or verb tense, and spelling mistakes, the misuse of vocabulary and errors on preposition. During the research, the researcher has recorded the numbers of each type of error appearing and calculated the corresponding frequency. Table 1 is the data summarization form.

TABLE 1

DATA SUMMARIZATION FORM ON ERROR RECORDING AND ANALYSIS Class_ SCORE_ DATE

\begin{tabular}{|l|l|l|}
\hline Error Types & Error Number & Error Frequency \\
\hline 1. Article errors & & \\
\hline 2. possessive / pronoun errors & & \\
\hline 3. subject-verb agreement errors & & \\
\hline 4. errors in singular or plural form of nouns & & \\
\hline 5. uninterrupted sentences & & \\
\hline 6. passive voice errors & & \\
\hline 7. conjunction errors & & \\
\hline 8. infinitive errors & & \\
\hline 9. -ing errors & & \\
\hline 10. Chinglish & & \\
\hline 11. verb tense errors & & \\
\hline 12. spelling errors & & \\
\hline 13. vocabulary misuse & & \\
\hline 14. preposition errors & & \\
\hline total & & \\
\hline
\end{tabular}

\section{B. Research Measurement and Design}

The research is carried out in one month in Beijing University of Posts and Telecommunications during the first 
semester of 2009-2010 academic years.

The unit of this research is class. Two classes are selected, and they are freshmen. Class One is a typical top-class and Class Two is typically at the opposite end. Each class has 30 non-English major students with same male-female ratio. In order to promote the validity of the research, the students selected are taught by one teacher with the same textbook and they do the same exercises. The times the teacher spends on each class are the same and the times that each student selected spends on learning and doing exercise are the same.

The research is achieved by collecting homework of the two classes for two times. Once the two classes were selected, they are assigned to do the same homework immediately and no copying is permitted.

TABLE 2

THE FIRST HOMEWORK

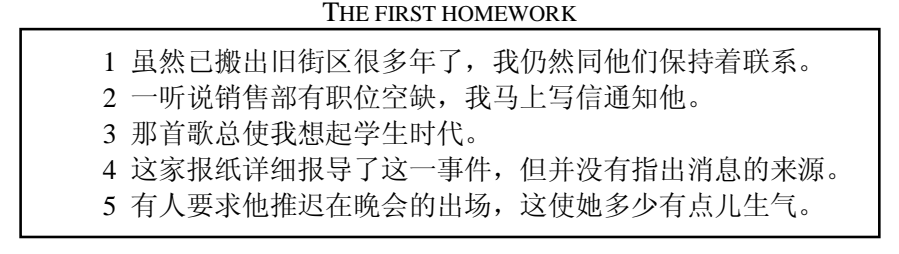

The researcher records the average score of each class as additional information and calculates the common errors made by the freshmen in their homework and fills the numbers in table1. Then the teacher takes Class One as Control Group and Class Two as Experimental Group. During one semester, the teacher just tells Class One the reference answers of the translation and offers them some phrases; while she hands off the translation error recording and analyzing forms as well as the bar diagrams and pie charts to Class Two with explanation and requires them to be aware of such errors all the time, especially the errors they are most likely to make. The teacher spends two hours on each class every three days and each student is required to do exercise for half an hour every day. Students in Class One cannot communicate with students in Class Two and copying answers is unacceptable.

The teacher assigns homework every other week (all together eight times for the whole semester), and with different methods in the two classes. The following table is the final homework:

TABLE 3

THE FINAL HOMEWORK

\begin{tabular}{|c|}
\hline $\begin{array}{l}1 \text { 许多外国留学生对京剧很痴迷。 } \\
2 \text { 他决定动身寻找印第安人的住处。 } \\
3 \text { 每当读学生的来信时, 这位老师的脸上总会绽放笑容。 } \\
4 \text { 这个研究小组完全投入到工作中, 并提前完成了科研项目。 } \\
5 \text { 那个模特非常漂亮, 苗条, 长着一双水汪汪的大眼睛。 }\end{array}$ \\
\hline
\end{tabular}

Similarly, the researcher records the average score of each class as additional information and calculates the errors and keeps the record separately for the two classes. After data collecting, it is time to do a thorough and systematic data analyzing.
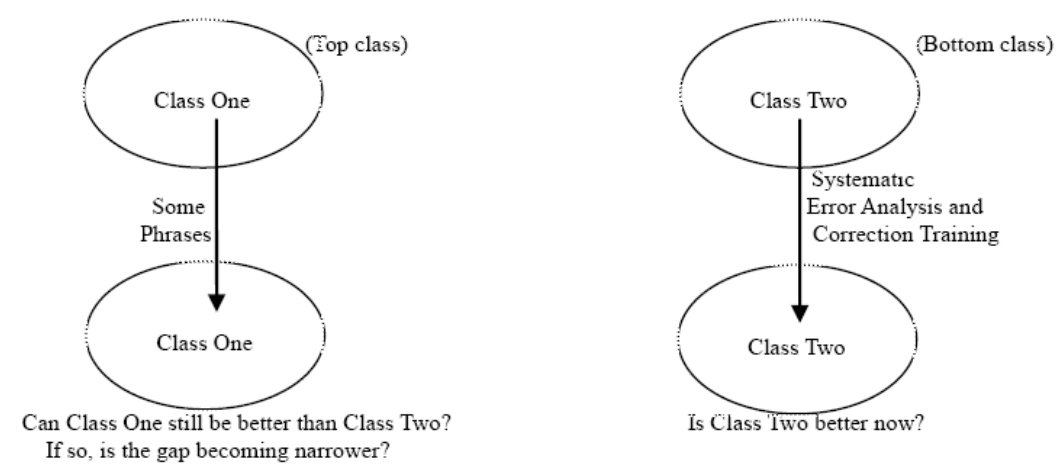

\section{DATA ANALYZING}

The data collected are: (1) the first and last homework of the two classes, together 600 sentence of sixty students; (2) Error recording and analyzing forms; (3) the average score of each class.

\section{A. Data Analysis of the First Homework}

The error recording and analyzing results for the first homework are as follows: 
TABLE 4

DATA SUMMARIZATION FORM ON ERROR RECORDING AND ANALYSIS FOR THE FIRST HOMEWORK

\begin{tabular}{|l|l|l|}
\multicolumn{2}{c}{ CLASS ONE SCORE 8.7 } & \multicolumn{2}{c|}{ DATE: OCT. 12, 2009 } \\
\hline Error Types & Error Numbers & Frequency (\%) \\
\hline 1. Article errors & 18 & 12.86 \\
\hline 2. possessive / pronoun errors & 10 & 7.14 \\
\hline 3. subject-verb agreement errors & 5 & 3.57 \\
\hline 4. errors on singular or plural form of nouns & 6 & 4.28 \\
\hline 5. uninterrupted sentences & 4 & 2.86 \\
\hline 6. passive voice errors & 0 & 0 \\
\hline 7. conjunction errors & 9 & 6.43 \\
\hline 8. infinitive errors & 3 & 2.14 \\
\hline 9. -ing errors & 4 & 2.86 \\
\hline 10. Chinglish & 14 & $\underline{10.00}$ \\
\hline 11. verb tense errors & 20 & $\underline{14.29}$ \\
\hline 12. spelling errors & 15 & $\underline{10.71}$ \\
\hline 13. vocabulary misuse & 21 & $\underline{15.00}$ \\
\hline 14. preposition errors & 11 & $\mathbf{7 . 8 6}$ \\
\hline total & 140 & $100 \%$ \\
\hline
\end{tabular}

\begin{tabular}{|c|c|c|}
\hline Class Two & DATE: 0 & 2009 \\
\hline Error Types & Error Numbers & Frequency $(\%)$ \\
\hline 1. Article errors & 35 & 12.20 \\
\hline 2. possessive / pronoun errors & 11 & 3.83 \\
\hline 3. subject-verb agreement errors & 14 & 4.88 \\
\hline 4. errors on singular or plural form of nouns & 9 & 3.14 \\
\hline 5. uninterrupted sentence & 11 & 3.83 \\
\hline 6. passive voice errors & 3 & 1.04 \\
\hline 7. conjunction errors & 14 & 4.88 \\
\hline 8. infinitive errors & 7 & 2.44 \\
\hline 9. -ing errors & 9 & 3.14 \\
\hline 10. Chinglish & 25 & $\underline{8.71}$ \\
\hline 11. verb tense errors & 37 & 12.89 \\
\hline 12. spelling errors & 31 & 10.80 \\
\hline 13. vocabulary misuse & 50 & $\overline{17.42}$ \\
\hline 14. preposition errors & 31 & 10.80 \\
\hline total & 287 & $100 \%$ \\
\hline
\end{tabular}

From table 4, we can see the error numbers and frequencies of each type of error separately. The average score of the first homework of Class One is 8.7 and Class Two is 7.3. The total errors of them are 140 and 287 separately. The following Bar charts and Pie charts can help us analyze the data better. (See Figure 1, 2)

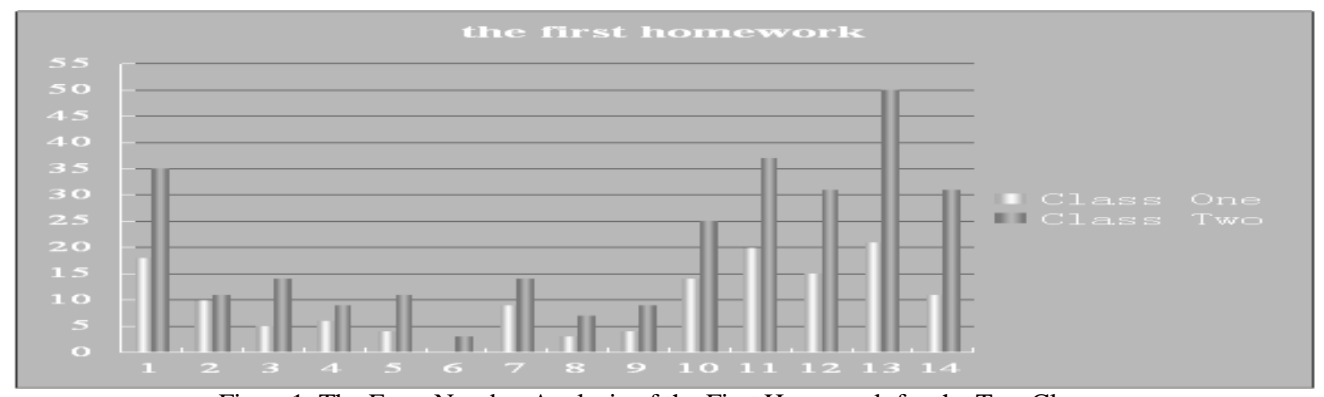

Figure1. The Error Number Analysis of the First Homework for the Two Classes

In Fig. 1, the numbers 1-14 of x-line represent the fourteen types of errors (the same hereinafter) and the white bars represent errors of Class One, while the black Class Two. The higher the bar is, the more the errors are. We can see that Class Two has more high bars than Class One and some bars of Class Two are even much higher than Class One. The total errors of Class Two are much more than that of Class One. So Class One does much better than Class Two as a whole.

From Fig. 2, we can see that the percentages of each type of error in the two classes are similar. The most common errors in Class One are vocabulary misuse, verb tense errors, article errors, spelling errors and Chinglish as well as proposition errors. They have the total percentage of 70.72. The most common errors in Class Two are also the six error categories, and the total percentage is 72.82. But Class Two students make more preposition errors than Chinglish errors. 


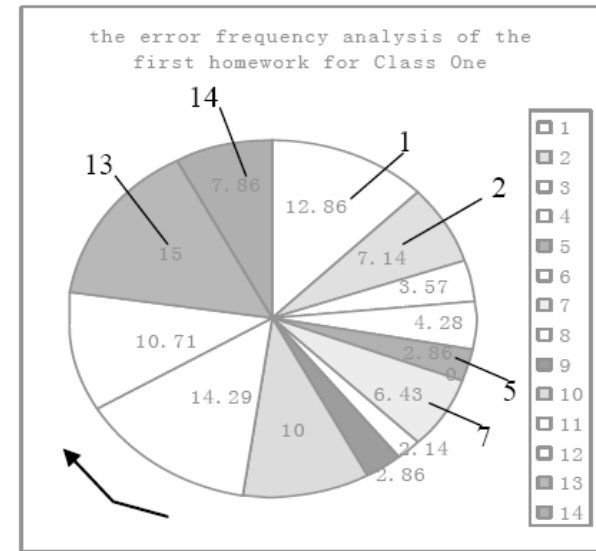

Top six errors occupy $70.72 \%$ Figure 2 the Error Frequency Analysis for the First Homework of Two Classes

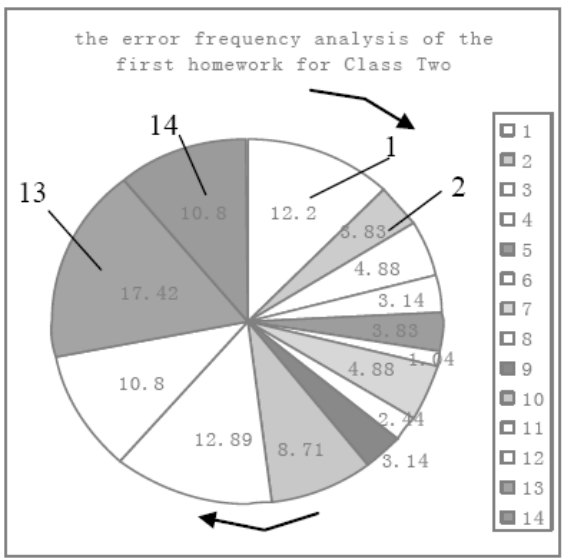
top six errors occupy $\underline{72.82 \%}$
Homework of Two Classes

\section{B. Data Analysis of the Final Homework}

When doing the final homework, Class One doesn't introduce error analysis approach to translation teaching, while Class Two has applied error analysis to the translation lectures. The error recording and analyzing results for the final homework are as follows:

TABLE 5

DATA SUMMARIZATION FORM ON ERROR RECORDING AND ANALYSIS FOR THE FINAL HOMEWORK

\begin{tabular}{|c|c|c|}
\hline $\begin{array}{rr}\text { ClASS ONE } & \text { SCORE 8.9 } \\
\end{array}$ & DATE: No & 2009 \\
\hline Error Types & Error Numbers & Frequency $(\%)$ \\
\hline 1. Article errors & 15 & 12.93 \\
\hline 2. possessive / pronoun errors & 9 & 7.76 \\
\hline 3. subject-verb agreement errors & 4 & 3.45 \\
\hline 4. errors on singular or plural form of nouns & 4 & 3.45 \\
\hline 5. uninterrupted sentence & 4 & 3.45 \\
\hline 6. passive voice errors & 0 & 0 \\
\hline 7. conjunction errors & 8 & 6.90 \\
\hline 8. infinitive errors & 2 & 1.72 \\
\hline 9. -ing errors & 0 & 0 \\
\hline 10. Chinglish & 13 & 11.21 \\
\hline 11. verb tense errors & 16 & $\overline{13.79}$ \\
\hline 12. spelling errors & 12 & 10.34 \\
\hline 13. vocabulary misusE & 18 & 15.52 \\
\hline 14. preposition errors & 11 & 9.48 \\
\hline total & 116 & $100 \%$ \\
\hline Class Two & DATE: No & 009 \\
\hline Error Types & Error Numbers & Frequency $(\%)$ \\
\hline 1. Article errors & 12 & 8.11 \\
\hline 2. possessive / pronoun errors & 7 & $\overline{4.73}$ \\
\hline 3. subject-verb agreement errors & 5 & 3.38 \\
\hline 4. errors on singular or plural form of nouns & 7 & 4.73 \\
\hline 5. uninterrupted sentence & 9 & 6.08 \\
\hline 6. passive voice errors & 5 & 3.38 \\
\hline 7. conjunction errors & 13 & 8.78 \\
\hline 8. infinitive errors & 7 & $\overline{4.73}$ \\
\hline 9. -ing errors & 5 & 3.38 \\
\hline 10. Chinglish & 19 & 12.84 \\
\hline 11. verb tense errors & 22 & 14.86 \\
\hline 12. spelling errors & 5 & 3.38 \\
\hline 13. vocabulary misusE & 21 & 14.19 \\
\hline 14. preposition errors & 11 & 7.43 \\
\hline total & 148 & $100 \%$ \\
\hline
\end{tabular}

From table5, we can see the error numbers and frequencies of each type of error separately. The average score of the final homework of Class One is 8.9 and Class Two is 8.7. The total errors of them are 116 and 148 separately. The following Bar charts and Pie charts can help us analyze the data better. (See Figure 3, 4) 


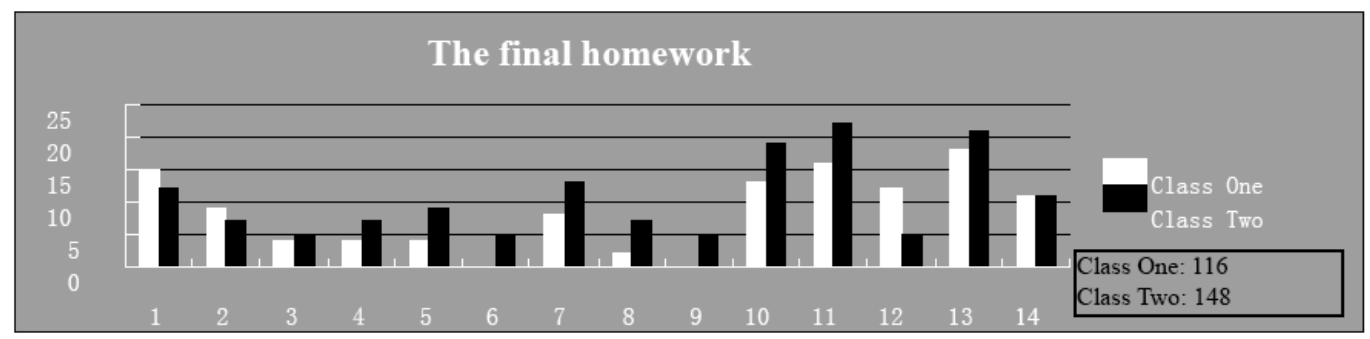

Figure 3 the Error Number Analysis of the Final Homework for the Two Classes

In Fig. 3, we can see that though Class Two has more high bars than Class One, every pair of the bars share similar heights. In some areas, students in Class Two do better than the students in Class One. The total numbers of errors are similar. So students in Class Two almost do the homework as well as the students in Class One as a whole.

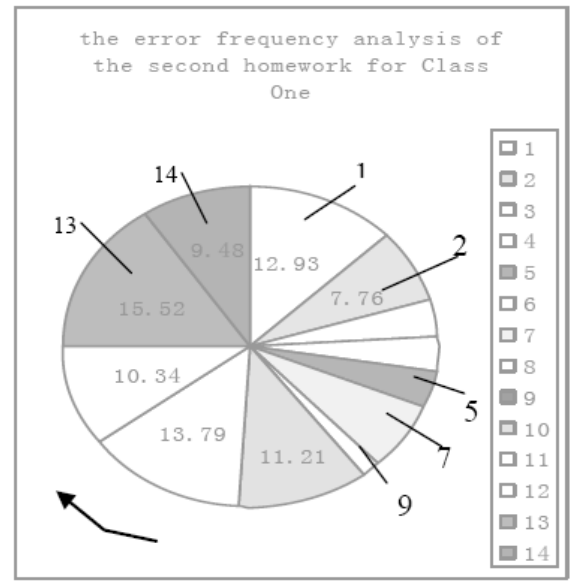

Top six errors occupy $\underline{73.27 \%}$

Figure 4 the Error Frequency

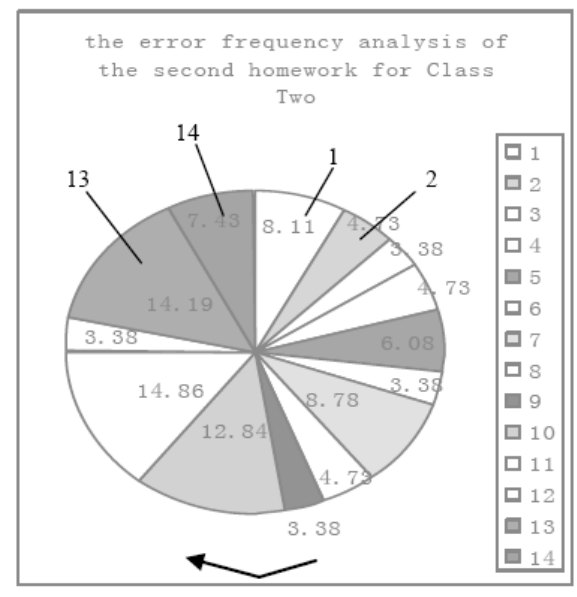

top six errors occupy $\underline{66.21 \%}$

From Fig. 4, we can see that the percentages of each type of error in the two classes are different. The most common errors in Class One are vocabulary misuse, verb tense errors, article errors, and Chinglish, spelling errors and preposition errors. The total percentage of them is 73.27. While the most common errors (in order) in Class Two are verb tense errors, vocabulary misuse, Chinglish, conjunction errors, article errors and preposition errors. The total percentage is 66.21, which is less than Class One. The order of the error types is different for the two classes. Students in Class One are more likely to make spelling mistakes, while students in Class Two are more likely to make conjunction mistakes.

\section{An Integrated Data Analysis}

We have analyzed the data separately, now it is time to make an integrated analysis.

a. An Integrated Average Score Analysis

Both Table 6 and Fig. 5 are the average scores of the two homeworks for the two classes.

TABLE 6

THE AVERAGE SCORE Form

\begin{tabular}{|c|c|c|}
\hline The Average Score & The first time & The last time \\
\hline Class One(Control) & 8.7 & 8.9 \\
\hline Class Two(Experiment) & 7.3 & 8.7 \\
\hline
\end{tabular}

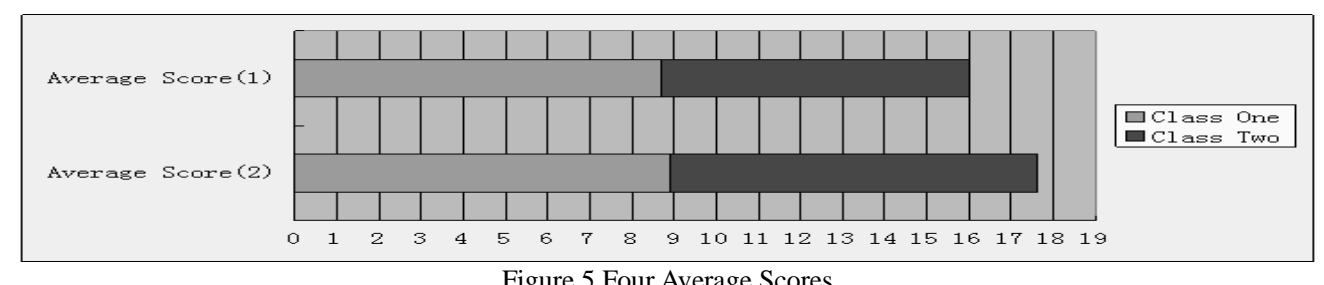

Figure 5 Four Average Scores

From the above table and bar chart, we can see that Class Two has made greater progress than Class One.

b. An Integrated Error Analysis

The above subsection has showed the integrated analysis on average scores, while this subsection will focus on the integrated analysis on errors. 


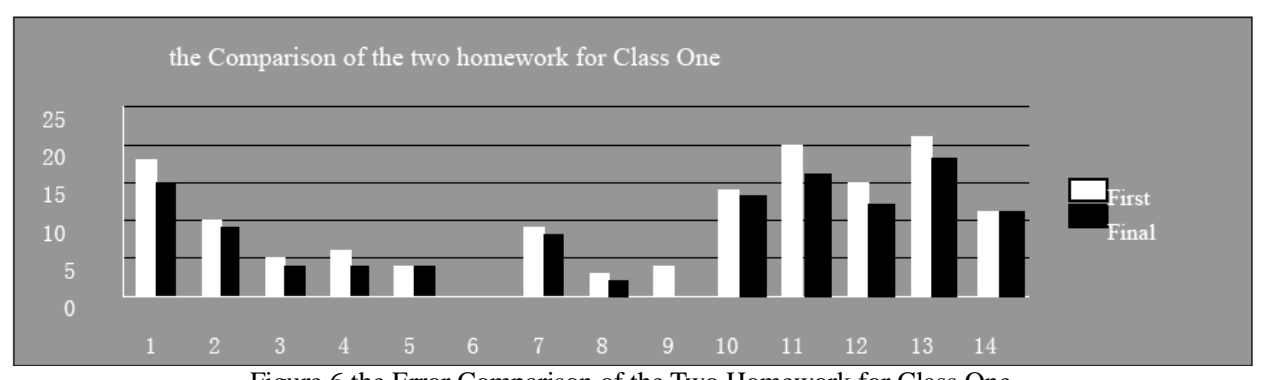

Figure 6 the Error Comparison of the Two Homework for Class One

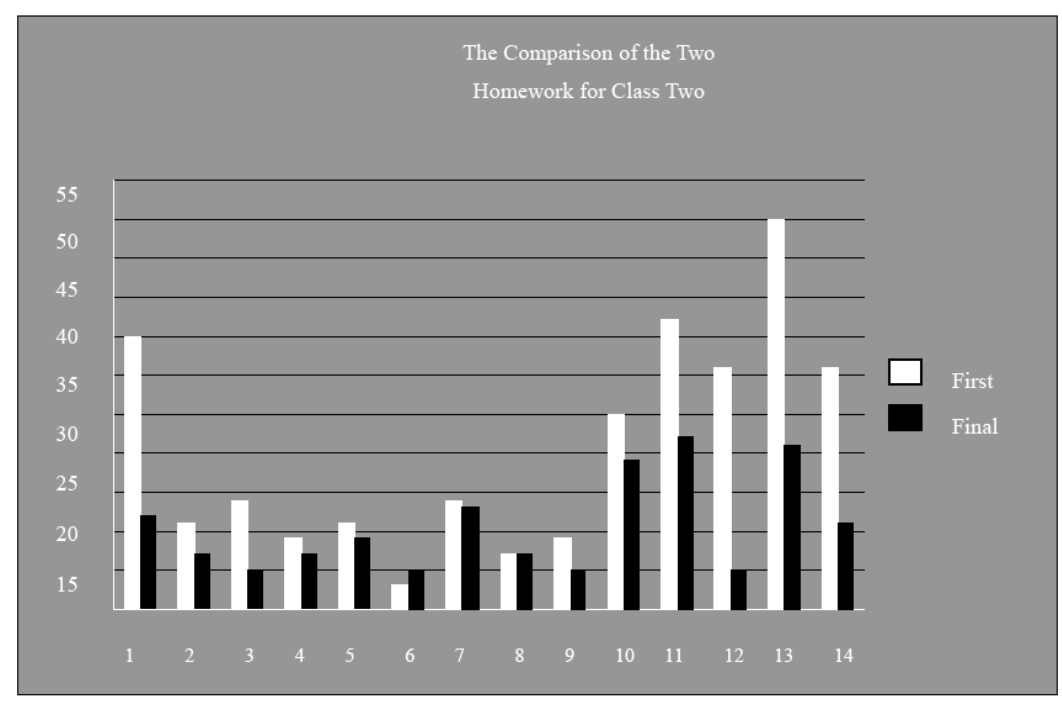

Figure 7 the Error Comparison for Class Two

From Fig. 6, we can see that the performance of students from Class One is relatively stable. But From Fig. 7, we can see that Class Two which has been taught with error analysis method in Chinese-English translation has made greater progress in their final translation homework.

c. An Integrated Error Frequency Analysis

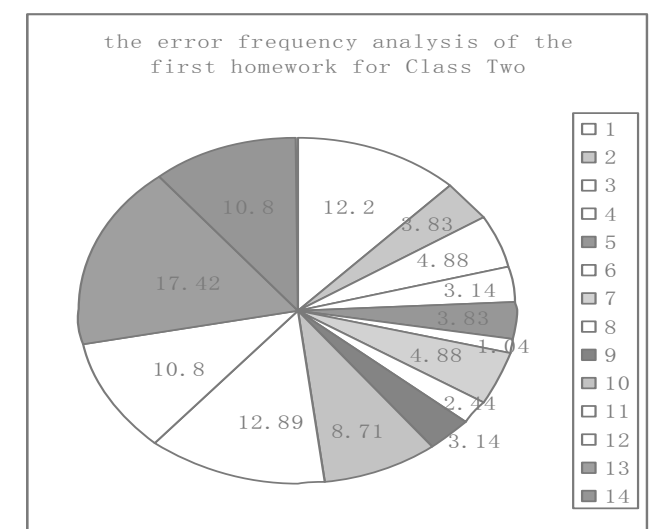

Top six errors occupy $\underline{\mathbf{7 2 . 8 2 \%}}$

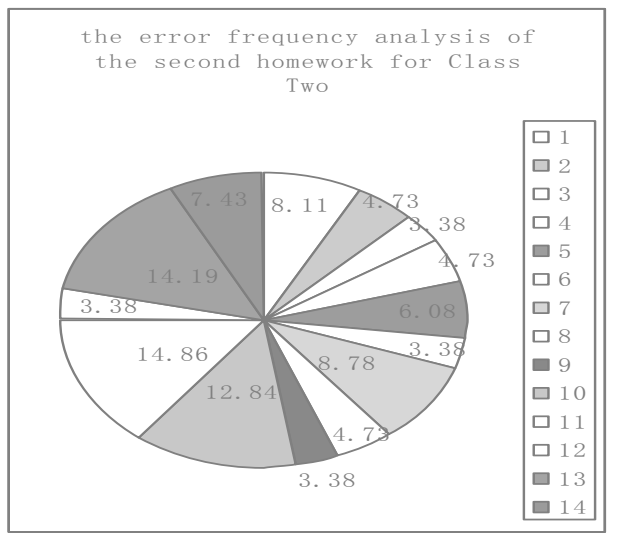

top six errors occupy $\underline{66.21 \%}$

Figure 8 Comparison of Error Frequency Analysis for Class Two

From Fig. 2, 4 and Fig. 8, we can see that for Class One, in the two assignments, the top six errors and the correlated frequencies are relatively stable, but for Class Two, the top six errors have some changes. The spelling errors of the final homework reduce sharply and this type of error has dropped out of the top six. Conjunction errors occupy a place in the top six. Besides that, the error frequencies of the two assignments of Class Two have more obvious changes than Class One. The total percentage of top six errors of the final homework has dropped obviously.

\section{CONCLUSION, LIMITATION AND IMPLICATIONS}

This research has mainly adopted the Quantitative method. In an attempt to analyze the common errors made by freshmen, it applies the error analysis approach to translation teaching in order to find out whether such an approach is feasible or not. By purposive sampling, it chose two typical classes with 60 non-English major freshmen in Beijing 
University of Posts and Telecommunications.

After a semester, the research reveals that the class which is taught with error analysis approach has made greater progress in Chinese-English translation. Thus error analysis could be applied to Chinese-English translation teaching area.

However, some factors unknown may affect the result of this research. Even the researcher has emphasized the importance of isolation, some students may still ask his/her classmates for help, or they may copy or help to revise others' answers. Other factors like carelessness, learning ability, etc. may affect their results.

Besides that, the samples in this research are selected by a non-random sampling procedure. Two classes cannot represent all freshmen in universities.

In spite of the limitations of it, this research still has its own values. When such issue is being discussed, this research could provide precious data for the researchers.

Finally this research may serve as an exploration for translation teaching strategies. With other approaches, error analysis method could improve the traditional teaching strategies. However, further researches are needed in this field, such as how to design a perfect environment and avoid the interference of other factors.

\section{ACKNOWLEDGEMENTS}

On the completion of my thesis, I should like to express my deepest gratitude to all those persons whose kindness and advice have made this research possible.

My sincere gratitude goes first to Professor Liu Aijun who has instructed me how to do a research and how to write an excellent research paper.

And I am greatly indebted to my supervisor, Professor Wang Baoling who has given me valuable instructions and rovided sufficient materials to me. With her guidance, I could analyze the materials and finish the research smoothly.

I am grateful to all the instructors who have instructed me with paper writing skills.

Last but not least, my gratitude is to my roommates, who have shared their ideas with me and constantly encouraged me when I felt frustrated.

\section{REFERENCES}

[1] Christopher D. Manning \& Hinrich Schütze. (1999). Foundations of Statistical Natural Language Processing. London: the MIT Press.

[2] Corder S.P. (1967). The Significance of Learners' Errors. International Review of Applied Linguistics 5, 161-169.

[3] Gary D. Bouma \& G.B.J. Atkinson. (1995). A Handbook of Social Science Research. Oxford: Oxford University Press.

[4] Gao Yuan. (2002). Contrastive Analysis and Error Analysis. Beijing: Beijing University of Aeronautics and Astronautics Press.

[5] Li Zhuqing \& Wang Lei. (2009). Error Analysis and Strategies Research on Translation of Higher Vocational-technical Schools. Journal of Shanxi Radio \& TV University 6, 71-72.

Yunhong Zhang was born in Hebei, China in 1986. She is currently a master student in Beijing University of Posts and Telecommunications. Her major is English Translation.

Baoling Wang was born in Qingdao, China in 1970. She received her M.A. degree in English Linguistics and Literature from Shandong University, China in 1996. She is currently an associate professor in the School of Humanities, Beijing University of Posts and Telecommunications, Beijing, China. Her research interests include English Teaching and E-C/C-E Translation. 